\title{
Ethnic/Racial Differences in 1-Year Persistence Rates by Institutional Status at Texas 4-Year Universities over Time
}

\author{
Rich Ballinger and John R. Slate \\ Department of Educational Leadership, Sam Houston State University, Huntsville, United States \\ Email: profslate@aol.com
}

\begin{abstract}
In this study, the 1-year persistence rates of four ethnic/racial groups (i.e., White, Black, Hispanic, and Asian) were analyzed as a function of institutional status (i.e., stayed or transferred) at Texas 4-year universities. Data were retrieved from the Texas Higher Education Coordinating Board Interactive Accountability system for the thirty-eight, 4-year Texas public universities for the 2014 academic year. For all ethnic/racial groups, statistically significant differences were present in the 1year persistence rates by institutional status. Effect sizes were very large. Regardless of race/ethnicity, students who transferred to another 4-year institution were statistically significantly less likely to persist than their peers who remained at the same 4-year institution. The 1-year persistence rates were $44 \%, 34 \%, 31 \%$, and $27 \%$ higher for Hispanic, White, Asian, and Black students, respectively, who stayed at the same institution than for Hispanic, White, Asian, and Black students who transferred to a different institution. Based upon these results, implications for policy and for practice for 4-year universities are provided, along with suggestions for future research.
\end{abstract}

Keywords: Persistence rates, institutional status, transfer students, White, Black, Hispanic students, 4-year universities

\section{Introduction}

The completion of a postsecondary degree can have a powerful influence on financial success and has necessitated the need for earning a degree. According to the Economic Report of the President, students who achieve a postsecondary degree earn more than twice as much money as students with just a high school diploma (Council of Economic Advisors, 2015). Furthermore, students who earn a college degree provide a skilled human resource for society, and are more likely to lead a healthy lifestyle and not increase healthcare costs in the economy, and are more likely to vote, volunteer, donate blood, and engage in other civic activities when compared to students who do not earn a college degree (Baum, Ma, \& Payea, 2013).

\subsection{Purpose}

The purpose of this empirical statewide analysis was to extend the research study conducted by Fauria and Slate (2014) in which they analyzed the effects of staying at or transferring to another institution by ethnicity/race for the 2000 and 2011 academic years. In this investigation, the 1-year persistence rate differences as a function of institutional status for four ethnic/racial groups (i.e., White, Black, Hispanic, and Asian) were examined. Specifically investigated in this study was whether the 1-year persistence rates of students enrolled in one of the thirty-eight, 4-year Texas public universities in the 2014 academic year differed by whether students remained or transferred to a different 4-year institution.

\section{$2 \quad$ Background}

Fauria and Slate (2014) investigated the persistence rates of different ethnic/racial groups (i.e., Black, Hispanic, White, and Asian) at the thirty-eight, 4-year Texas public universities. They analyzed the effect of staying at or transferring to another institution by ethnic background. Data were collected from the Texas Higher Education Coordinating Board Interactive Accountability System for the 2000 and 2011 academic years. Fauria and Slate (2014) documented that regardless of ethnic/racial memberships 
those students who stayed at the same 4-year public university had higher 1-year persistence rates than students who transferred to a different 4-year university. Students who stayed at the same institution were $45 \%$ more likely to persist than were their peers who transferred to a different postsecondary institution (Fauria \& Slate, 2014).

In a similar study but with community college students, Moss and Slate (2016) investigated the 1year persistence rates of Black and White students. Specifically, they examined the effect of institutional status (i.e., stayed or transferred) on 1-year persistence rates of Texas community college students. Data were collected from the Texas Higher Education Coordinating Board Interactive Accountability System for the 70 Texas community colleges in the 2000 academic year and the 73 Texas community colleges in the 2013 academic year. Moss and Slate (2016) documented that the 1-year persistence rates were over $36 \%$ higher when Black and White students remained at the same institution compared to transferring to another institution. Moss and Slate (2016) recommended that community colleges and other key stakeholders find ways to increase retention and completion rates. In a similar study, Spangler and Slate (2015) analyzed graduation and retention rates of Texas community college students by ethnic/racial membership (i.e., White, Black, Hispanic, and Asian). Data were collected from the Texas Higher Education Coordinating Board Interactive Accountability System for the 2000 and 2004 through the 2010 academic years. Spangler and Slate (2015) established that graduation and persistence rates for every ethnic/racial group increased between the 2000 and 2010 academic years. Graduation and persistence rates between 2000 and 2010 were $8.45 \%, 8.27 \%, 9.78 \%$, and $11.6 \%$ higher for White, Black, Hispanic, and Asian students, respectively. They acknowledged this improvement and recommended that more specific target goals be identified for Texas community colleges because of the expansive enrollments of students at these institutions.

In contrast to the previous studies mentioned, Keels (2013) investigated gender and ethnic/racial gaps in course grades and graduation rates at 24 predominantly White institutions. Data were collected from a 1999 cohort group and included 966 White, 953 Black, 924 Asian, and 885 Hispanic students. Keels (2013) documented that White and Asian students had the highest average GPA, 3.3, Hispanic students had an average 3.1 GPA, and Black students had an average 3.0 GPA. Additionally, 6-year graduation rates were $92 \%$ for White students, $90 \%$ for Asian students, $86 \%$ for Hispanic students, and $80 \%$ for Black students. Keels (2013) concluded that institutions should create supportive social communities for different ethnic/racial groups that would provide them the necessary resources to aid in retention and graduation rates.

In another important study, Reid and Moore (2008) investigated how first-generation Black and immigrant college and university students perceived their preparedness for a postsecondary education. The findings centered around two themes: (a) skills that aided students in preparation for a postsecondary education and (b) skills that lacked in preparation of the college experience. Reid and Moore (2008) concluded that preparation starts well before enrollment in a college or university and must be a commitment from both family and the schools that the student has attended. Teachers must be encouraging, serve as positive role models, and administrators must make sure that students are provided with a curriculum with the necessary knowledge and skills. School counselors should be a resource to help students navigate college enrollment. Moreover, postsecondary institutions should recognize these students and provide them with opportunities to help them feel comfortable in the college or university setting (Reid \& Moore, 2008).

Following Reid and Moore (2008), Cox, Joyner, and Slate (2011) investigated the graduation rates of Hispanic students in Texas since 2000. Data were collected from 76 community colleges in Texas through the Texas Higher Education Coordinating Board Interactive Accountability System. Cox et al. (2011) established that the average number of degrees earned by Hispanic students increased every year from 2000 through the 2008 academic years. Due to the increase in the Hispanic population over this time period, the number of Hispanic students who received a degree increased. Of importance in their study, however, was that the percentage of degrees received by Hispanic students did not increase. Cox et al. (2011) recommended that further research was needed regarding Hispanic student graduation rates because their educational attainment was lower than that of other groups. In another study on Hispanic students, Boden (2011) analyzed data on first-generation Hispanic students and their perceptions of their academic preparedness for a postsecondary education. Boden (2011) documented four common themes during the semi-structured interviews: (a) education planning, (b) guides, (c) academic skills, and (d) personal impetus. Students wanted the opportunity to improve themselves and their families, 
the ability to find an education mentor, and access to and understanding of the necessary academic skills. Mentor programs should be considered to assist these students when they initially enroll in postsecondary settings. Boden (2011) also recommended that enrollment at a community college before high school graduation can help the student transition to postsecondary life. Postsecondary institutions should recognize the need for support for Hispanic students. Further research should be completed to find ways to aid them in their academic success (Boden, 2011).

\subsection{Significance of the Study}

Earning a degree positively influences individuals and society, however, an increasing number of students who enroll at a college or university are not earning a degree (Carey, 2004). In fact, many universities lose more than $25 \%$ of the freshman class in the first year alone with underrepresented students (i.e., low-income students, Black, and Hispanic) faring even poorer (Carey, 2004). In a study in which 1-year persistence rates by ethnic/racial groups were investigated, Fauria and Slate (2014) established that regardless of ethnic/racial group, students who stayed at the same institution rather that transferring were much more likely to persist. In fact, the 1-year persistence rate for all ethnic/racial groups was $60 \%$ for students who stayed at the same institution compared to an abysmally low rate, 15\%, for those students who transferred for the 2000 and 2011 academic years (Fauria \& Slate, 2014). Despite federal mandates to promote college readiness and enforce strict state standards, the issue of college readiness and graduation rates continues to be an issue for higher education and federal and state government (Fauria \& Slate, 2014).

\section{$2.2 \quad$ Research Questions}

The following research questions were addressed in this study: (a) What is the difference in the 1-year persistence rate as a function of institutional status for White students at Texas 4-year public universities?; (b) What is the difference in the 1-year persistence rate as a function of institutional status for Black students at Texas 4-year public universities?; (c) What is the difference in the 1-year persistence rate as a function of institutional status for Hispanic students at Texas 4-year public universities?; and (d) What is the difference in the 1-year persistence rate as a function of institutional status for Asian students at Texas 4-year public universities?

\section{Method}

\subsection{Participants}

The data for this study were retrieved through the Texas Higher Education Coordinating Board Interactive Accountability System database. Students were categorized by ethnicity/race (i.e., White, Black, Hispanic, and Asian) and attended classes full-time during the 2014 academic year from one of the thirty-eight, 4-year universities in Texas. Students' 1-year persistence rates, as a function of institutional status (i.e., staying or transferring), were analyzed for this study.

\subsection{Instrumentation and Procedures}

Data were acquired from the Texas Higher Education Coordinating Board Interactive Accountability System and downloaded into Microsoft Excel. The Texas Higher Education Coordinating Board makes publicly available an extensive array of data on student performance at 4-year universities, as well as at community colleges. The data that were downloaded from this publicly available website were then recoded into a SPSS format for statistical analysis. For the purpose of this study, the term 1-year persistence rate was defined as "percent of first-time entering, degree-seeking undergraduates enrolled in at least 12 semester credit hours $(\mathrm{SCH})$ in the fall semester who still enrolled at the same or another institution the following fall" (Texas Higher Education Coordinating Board, 2016, p. 4). 


\subsection{Research Design}

A quantitative, non-experimental research design, specifically a causal-comparative design, was used for this study (Creswell, 2013). Causal comparative research allows the researcher to investigate and compare two or more groups in terms of an independent variable that has already occurred (Creswell, 2013). In this study, the independent variable was institutional status (i.e., staying or transferring). The dependent variables were 1-year persistence rates for four ethnic/racial groups (i.e., White, Black, Hispanic, and Asian). Both variables had already occurred in this study.

\section{Results}

Prior to conducting inferential statistics, to determine whether a statistically significant difference was present between 1-year persistence rates for students who remained at the same institution compared to those students who transferred to another institution, normality checks were conducted. These checks were conducted separately for each of the four ethic/racial groups of students. Of the standardized skewness coefficients (i.e., the skewness value divided by its standard error) and the standardized kurtosis coefficients (i.e., the kurtosis value divided by its standard error), three of the four dependent variables had values that were within the limits of normality, $+/-3$ (Onwuegbuzie \& Daniel, 2002). For consistency in the inferential statistical procedures that were used, a decision was made to use the parametric dependent samples $t$-test in all four analyses. Dependent samples $t$-tests are an appropriate inferential statistical procedure to calculate when the scores in one variable are related to the scores in another variable (Slate \& Rojas-LeBouef, 2011). In this investigation, 1-year persistence rates were present by ethnic/racial groups (i.e., White, Black, Hispanic, and Asian) and were at the interval/ratio level of measurement.

With respect to White students, the parametric dependent samples $t$-test analysis yielded a statistically significant difference in 1-year persistence rates, $t(32)=6.35, p<.001$, Cohen's $d=1.43$, a large effect size (Cohen, 1988), as a function of institutional status. White students had a statistically significantly higher 1-year persistence rate when staying at the same institution than did White students who transferred to another institution. In fact, White students were twice as likely to persist when staying at the same institution than when transferring to another institution. Depicted in Table 1 are the descriptive statistics for this analysis.

Table 1. Descriptive statistics for white students' 1-year persistence rates by institutional status

\begin{tabular}{l|l|l}
\hline Institutional Status & $M \%$ & $S D \%$ \\
\hline Stayed & 67.84 & 12.97 \\
\hline Transferred & 34.07 & 30.81 \\
\hline
\end{tabular}

For Black students, the parametric dependent samples $t$-test analysis yielded a statistically significant difference in 1-year persistence rates by institutional status, $t(32)=4.55, p<.001$, Cohen's $d=1.09$, a large effect size (Cohen, 1988). Black students had a statistically significantly higher 1-year persistence rate when staying at the same institution compared to Black students who transferred to another institution. Black students were $27 \%$ more likely to persist when staying at the same institution than Black students who transferred to another institution. Table 2 contains the descriptive statistics for this analysis.

Table 2. Descriptive statistics for black students' 1-year persistence rates by institutional status

\begin{tabular}{l|l|l}
\hline Institutional Status & $M \%$ & $S D \%$ \\
\hline Stayed & 61.88 & 19.68 \\
\hline Transferred & 34.94 & 29.04 \\
\hline
\end{tabular}

Concerning Hispanic students, the parametric dependent samples $t$-test analysis yielded a statistically significant difference in 1-year persistence rates by institutional status, $t(33)=9.12, p<.001$, Cohen's $d$ 
$=2.45$, a large effect size (Cohen, 1988). Hispanic students who stayed at the same institution had a statistically significantly higher 1-year persistence rate than Hispanic students who transferred to another institution. Of note was that Hispanic students were three times more likely to persist when staying at the same institution compared to transferring to another institution. Descriptive statistics for this analysis are revealed in Table 3.

Table 3. Descriptive statistics for hispanic students' 1-year persistence rates by institutional status

\begin{tabular}{l|l|l}
\hline Institutional Status & $M \%$ & $S D \%$ \\
\hline Stayed & 66.44 & 15.74 \\
\hline Transferred & 21.75 & 20.37 \\
\hline
\end{tabular}

With respect to Asian students, the parametric dependent samples $t$-test analysis yielded a statistically significant difference in 1-year persistence rates by institutional status, $t(31)=4.96, p$ $<.001$, Cohen's $d=1.32$, a large effect size (Cohen, 1988). Asian students who stayed at the same institution had a statistically significantly higher 1-year persistence rate than Asian students who transferred to another institution. Asian students were 31\% more likely to persist when they stayed at the same institution than did Asian students who transferred to another institution. Depicted in Table 4 are the descriptive statistics for this analysis.

Table 4. Descriptive statistics for asian students' 1-year persistence rates by institutional status

\begin{tabular}{l|l|l}
\hline Institutional Status & $M \%$ & $S D \%$ \\
\hline Stayed & 71.67 & 17.22 \\
\hline Transferred & 40.84 & 28.07 \\
\hline
\end{tabular}

\section{Discussion}

As previously mentioned, the research investigation conducted by Fauria and Slate (2014) was extended in this article. Fauria and Slate (2014) analyzed the effect of staying at or transferring to another 4-year institution by ethnicity/race for the 2000 and 2011 academic years. Fauria and Slate (2014) documented that regardless of ethnic/racial membership those students who stayed at the same 4-year public university had statistically significantly higher 1-year persistence rates than those students who transferred. In their investigation, 1-year persistence rates for White students who did not transfer were $49 \%$ higher than for White students who transferred. Black students, in their study, had 1-year persistence rates for students who did not transfer that were $50 \%$ higher than for Black students who transferred. Hispanic students, in their study, had 1-year persistence rates for students who stayed that were $49 \%$ higher for Hispanic students who transferred. Finally, for Asian students, Fauria and Slate (2014) documented that their 1-year persistence rates were $54 \%$ higher for Asian students who stayed than for Asian students who transferred to a different 4-year institution.

The focus of this study was on the 1-year persistence rates for four ethnic/racial groups (i.e., White, Black, Hispanic, and Asian) in the 2014 academic year. For all four ethnic/racial groups, statistically significant differences were yielded in the 1-year persistence rates by student institutional status. Regardless of race/ethnicity, students who transferred to a different 4-year institution were much less likely to persist than were their counterparts who stayed at the same 4-year institution.

Results of this statewide analysis were congruent with the results of the Fauria and Slate (2014) investigation. The 1-year persistence rate for White students who stayed was $34 \%$ higher than for White students who transferred (see Table 2). For Black students, 1-year persistence rates for students who stayed was $27 \%$ higher than for Black students who transferred (see Table 2). For Hispanic students, 1year persistence rate for those who stayed was $44 \%$ higher than for those who transferred (see Table 3 ). Finally, for Asian students, 1-year persistence rate for those who stayed was $31 \%$ higher than for those who transferred (see Table 4). 
The results of this study provide a compelling rationale to encourage students of all ethnic/racial groups to remain at the same institution rather than transferring to another institution. With this information available and with analyzing this issue, many questions arise. What are the specific reasons that students transfer and how can these reasons be overcome? Can high school counselors or other high school staff make this a point of emphasis when discussing college/university choices with high school students? What can colleges or universities do, in addition to existing student success/retention programs, to assist students in their acclimation to college/university life and lessen the chances of the students transferring? With many states moving toward Performance Based Funding, will colleges and universities be less likely to admit transfer students because of the negative influence on retention and graduation rates (Dougherty \& Reddy, 2011). Clearly, this topic is complex and worthy of future research.

Finally, it is important to note that this study was delimited to the thirty-eight, 4-year Texas public universities during the 2014 academic year. Results in this study should not be overgeneralized to other states or to community colleges. Furthermore, only four ethnic/racial groups (i.e., White, Black, Hispanic, and Asian) were taken into consideration for this study and did not include other ethnic/racial groups. Readers are urged to be cautious in the degree to which they generalize results from this investigation.

\section{References}

1. Baum, S., Ma, J., \& Payea, K. (2013). Education pays 2013: The benefits of higher education for individuals and society. Retrieved from https://trends.collegeboard.org/sites/default/files/education-pays-2013-full-report.pdf.

2. Boden, K. (2011). Perceived academic preparedness of first-generation Latino college students. Journal of Hispanic Higher Education, 10(2), 96-106. doi:10.1177/1538192711402211.

3. Carey, K. (2004). A matter of degrees: Improving graduation rates in four-year colleges and universities. Washington, DC: The Education Trust. Retrieved from http://edtrust.org/wpcontent/uploads/2013/10/highered.pdf.

4. Cohen, J. (1988). Statistical power analysis for the behavioral sciences (2nd ed.). Hillsdale, NJ: Lawrence Erlbaum.

5. Council of Economic Advisors. (2015). Economic report of the President: Together with the annual report of the Council of Economic Advisors. Washington, DC: Government Printing Office. Retrieved from http://www.gpo.gov/fdsys/browse/collection.action?collectionCode=ERP.

6. Cox, S., Joyner, S. A., \& Slate, J. R. (2011). Differences in Hispanic graduation rates at Texas community colleges over time. Community College Enterprise, 17(2), 62-67. Retrieved from http://www.schoolcraft.edu/pdfs/cce/17.2.62-76.pdf.

7. Creswell, J. W. (2013). Research design: Qualitative, quantitative, and mixed methods approaches (4th ed.) Thousand Oaks, CA: Sage.

8. Dougherty, K. J., \& Reddy, V. (2011). The impacts of state performance funding systems on higher education institutions: Research literature review and policy recommendations. CCRC working paper No. 37, Community College Research Center. CCRC Publications. Teachers College, Columbia University, New York, NY. Retrieved from http://ccrc.tc.columbia.edu/media/k2/attachments/impacts-state-funding-higher-education.pdf.

9. Fauria, R. M., \& Slate, J. R. (2014). Persistence rate differences of university students by race: A within groups comparison. International Journal of University Teaching and Faculty Development, 4(1), 1-10. Retrieved from http://search.proquest.com/openview/701c2c2421fe3741e77ec8cacb1ce0a7/1?pq-origsite=gscholar\&cbl=2034856.

10.Keels, M. (2013). Getting them enrolled is only half the battle: College success as a function of race or ethnicity, gender, and class. American Journal of Orthopsychiatry, 83(2-3), 310-322. doi:10.1111/ajop.12033.

11.Moss, S., \& Slate, J. R. (2016). Differences in Black and White students' persistence rates in Texas community colleges by institutional status. Journal of Basic and Applied Research International, 13(4), 206-213.

12.Onwuegbuzie, A. J., \& Daniel, L. G. (2002). Uses and misuses of the correlation coefficient. Research in the Schools, 9(1), 73-90.

13.Reid, J. M., \& Moore, J. L., III. (2008). College readiness and academic preparation for postsecondary education: Oral histories of first-generation urban college students. Urban Education, 43, 240-260. doi:10.1177/0042085907312346. 
14.Slate, J. R., \& Rojas-LeBouef, A. (2011). Calculating basic statistical procedures in SPSS: A self-help and practical guide to preparing theses, dissertations, and manuscripts. Ypsilanti, MI: NCPEA Press.

15.Spangler, J. M., \& Slate, J. R. (2015). Texas community college graduation and persistence rates as a function of student ethnicity. Community College Journal of Research and Practice, 39(8), 741-753. doi:10.1080/10668926.2013.878261.

16.Texas Higher Education Coordinating Board. (2016). Accountability section. Retrieved from http://www.txhighereddata.org/Interactive/Accountability/. 